\title{
Synthesis of gold nanoparticles with Solanum xanthocarpum extract and their in vitro anticancer potential on nasopharyngeal carcinoma cells
}

This article was published in the following Dove Press journal: International Journal of Nanomedicine

\author{
Pengfei Zhangl,* \\ Peicheng Wang 2 ,* \\ Lei Yan ${ }^{3}$ \\ Lifeng Liu' \\ 'Department of Otolaryngology - \\ Head and Neck Surgery, The First \\ Affiliated Hospital of Xi'an Jiaotong \\ University, Xi'an, Shaanxi 71006I, \\ China; ${ }^{2}$ Department of \\ Otolaryngology - Head and Neck \\ Surgery, Weihai Municipal Hospital, \\ Weihai, Shandong 264200, China; \\ ${ }^{3}$ Innoscience Research Sdn. Bhd, \\ Subang Jaya, Selangor 47500, Malaysia \\ *These authors contributed equally \\ to this work
}

\begin{abstract}
Background: Nasopharyngeal cancer (NPC) is one of the subtypes of head and neck cancers. It occurs rarely, and its prevalence depends mainly on geographical location. Modern-day research is focused on coupling nanotechnology and traditional medicine for combating cancers. Gold nanoparticles (AuNPs) were synthesized from Solanum xanthocarpum (Sx) leaf extract using reduction method.
\end{abstract}

Methods: Characterization of the synthesized AuNPs was done by different techniques such as ultraviolet-visible spectrum absorption, X-ray diffraction, dynamic light scattering, Fourier transform infrared spectroscopy, transmission electron microscopy, and energy-dispersive X-ray analysis.

Results: All the results showed the successful green synthesis of AuNPs from Sx, which induced apoptosis of C666-1 cell line (NPC cell line). There was a decline in both cell viability and colony formation in C666-1 cells upon treatment with Sx-AuNPs. The cell death was proved to be caused by autophagy and mitochondrial-dependent apoptotic pathway.

Conclusion: Thus, due to their anticancer potential, these nanoparticles coupled with Sx can be used for in vivo applications and clinical research in future.

Keywords: Solanum xanthocarpum, gold nanoparticle, C666-1 cells, ROS, apoptosis

\section{Introduction}

Cancer that arises in the epithelial cells covering the nasopharynx is termed as nasopharyngeal cancer (NPC), which is one of the subtypes of head and neck cancers. ${ }^{1}$ Although the exact cause of NPC is unknown, its incidence has a strong correlation with Epstein-Barr virus and to a lesser extent with heredity or intake of tobacco and alcohol. Approximately 65,000 deaths were accounted worldwide in the year $2010{ }^{2}$ NPC is unique in that its prevalence is dependent on racial and geographical variations. It is a rare type of cancer that usually affects the populations of Southeast Asia (67\%), Southern China, and North America. ${ }^{3-5}$ The incidence of NPC is two- to three-fold higher in males, ${ }^{6-8}$ and the incidence peaks usually between 50 and 60 years and mortality is reported over 85 years of age. ${ }^{9,10}$ According to the WHO, there are three subtypes of NPC identified, viz squamous cell carcinoma (affects adults), non-keratinizing carcinoma, and undifferentiated carcinoma (mostly found in children). ${ }^{11}$

The emergence of nanotechnology in the field of cancer medicine has paved way for countless research studies. Chemotherapeutics used in this era pose a potential demerit of nontargeted approach, which results in the death of normal cells as well. Hence, targeted drug delivery system will be of much help in destroying only cancer cells leaving normal cells intact. Moreover, nanoparticles coupled with cancer drugs help in the improvement of their pharmacokinetic properties.
Correspondence: Lifeng Liu Department of Otolaryngology - Head and Neck Surgery, The First Affiliated Hospital of Xi'an Jiaotong University, No 277 Yanta West Road, Xi'an, Shaanxi 7I006I, China

Email z8553406@sina.com $\mathrm{BY}$
he for commercial use of this work, please see paragraphs 4.2 and 5 of our Terms (https://www.dovepress.com/terms.php). 
Various nanoparticles have been targeted against NPC till date. Prasanth and Gopinath ${ }^{12}$ showed that zinc oxide nanoparticles decreased the rate of respiration of NPC cells. Another study used a combination of lipid nanoparticles and a fusion peptide containing NPC-specific therapeutic peptide, which significantly suppressed the growth of NPC tumors, improved the therapeutic efficacy, and increased the rate of survival. ${ }^{13}$

One such nanoparticle used in the treatment of NPC is gold nanoparticle (AuNP). AuNPs are commonly preferred for conjugation with drugs because of their better optical nature and biocompatibility. ${ }^{14,15}$ AuNPs are also preferred because they are stable, nontoxic, and very small. Despite plenty of modern-day cancer medicines coming into market consistently, plant-based molecules earn cardinal importance due to their less aftereffects and good bioavailability.

In general, synthesis of AuNPs has been achieved using methods such as citrate reduction method, ${ }^{16}$ sodium borohydride reduction method, ${ }^{17}$ and so on, which utilize hazardous chemicals and toxic solvents. Other techniques used for nanoparticle synthesis are ion sputtering, sol-gel method, hydrothermal method, etc. However, in the field of medicine, it is mandatory to use nanoparticles that are synthesized by natural (green synthesis) or safe methods.

The synthesis of AuNPs with the help of plant extracts is highly beneficial as it reduces the harmful effects of chemicals. It can also be used for large-scale production and is cost-effective. Plant extracts can serve as reducing, capping, and stabilizing agents in the production of nanoparticles, and have therefore gained much attention in modern research. ${ }^{18}$ Moreover, medicinal plants are commonly used for the synthesis of nanoparticles..$^{19,20}$

Solanum xanthocarpum (Sx) belongs to the family Solanaceae and is found in wastelands and along roadsides. ${ }^{21}$ Fruits of this plant are edible and used as food as well as medicine. Various biological properties have been reported for Sx, which include antioxidant, antifertility, antifungal, anti-inflammatory, anti-HIV, anti-allergic, and natriuretic properties. ${ }^{22-25}$ Traditionally, Sx has been used in the treatment of respiratory, gastrointestinal (GI), urinary, and cardiac problems, gonorrhea, fever, and bleeding piles. Sx plants possess abundant bioactive compounds such as flavonoids, saponins, alkaloids (eg, solasodine), glycosides, and so on.

Although Sx has been proved to have ample medicinal applications, its anticancer potential on NPC has not been extensively studied. A glycoalkaloid of Sx, solmargine, was shown to induce apoptosis in a human hepatoma cell line (Hep3B). ${ }^{26}$ Nonpolar extracts of Sx fruits were found to be $\sim 91 \%$ toxic to THP-1 leukemia cells, while they exhibited $70 \%$ growth inhibition on HOP-62 lung cancer cell line. ${ }^{24}$

This study was, therefore, designed to analyze the anticarcinogenic potential of AuNPs synthesized from Sx on NPC. The rationale behind this study is that Sx possesses good antioxidant property, and hence, should possibly be anticarcinogenic. Moreover, the idea of synthesizing AuNPs from Sx makes the nanoparticles more biocompatible and advantageous.

\section{Materials and methods Materials}

C666-1 cells were obtained from the Institute of Biochemistry and Cell Biology, Chinese Academy of Sciences (Shanghai, China), cultured in recommended culture media supplemented with $10 \% \mathrm{FBS}$, and were maintained in $5 \% \mathrm{CO}_{2}$ at $37^{\circ} \mathrm{C}$. At $70 \%-80 \%$ confluency, cells were passaged using trypsin-EDTA solution. Auric chloride $\left(\mathrm{AuCl}_{3}\right)$, dimethyl sulfoxide (DMSO), and all other reagents were procured from Sigma-Aldrich (St Louis, MO, USA).

\section{Synthesis and purification of AuNPs from Sx}

Sx was collected from an area around $\mathrm{Xi}$ 'an and authenticated by the Jiaotong University, Xi'an, Shaanxi, China. The plant was washed thoroughly with running tap water and rinsed twice with distilled water. Ten grams of the leaves was boiled along with $100 \mathrm{~mL}$ of sterile distilled water for 5 minutes. The plant extract was separated and stored. To $45 \mathrm{~mL}$ of freshly prepared $1 \mathrm{mM}$ auric chloride solution, $5 \mathrm{~mL}$ of the Sx leaf extract was added and stirred gently and continuously. This mixture was incubated for various time points and monitored by ultraviolet (UV)-visible absorption spectroscopy from day 1 to day 30. In this procedure, auric ions present in auric chloride are reduced by the plant extract (reducing agent) to metallic gold $\left(\mathrm{Au}^{0}\right)$ nanoparticles. The AuNPs produced from this procedure were then centrifuged at 12,000g for 30 minutes, purified, and stored.

\section{Characterization of AuNPs}

\section{UV-visible spectrum absorption}

To analyze the formation and stability of AuNPs, a doublebeam UV-visible spectrophotometer (Shimadzu, Kyoto, Japan) was used in the wavelength range of 300-700 nm. The color change and formation of nanoparticles were recorded at 24 hours, 48 hours, 15th day, and 30th day. The spectroscopic analysis was done in fresh samples at room temperature (RT). 


\section{X-ray diffraction}

The AuNP samples were spun at $10,000 \times g$ for 15 minutes, the pellet was washed thrice with distilled water, and the sample was freeze-dried. An X-ray diffraction (XRD) pattern was obtained by MAXima_X XRD-7000 (Shimadzu) operating at $40 \mathrm{kV}$ and a $30 \mathrm{~mA}$ electrical current with $\mathrm{Cu}-\mathrm{K} \alpha$ radiation $(\lambda=1.5404 \AA)$, and the $2 \theta$ scanning range was $30^{\circ}-75^{\circ}$.

\section{Dynamic light scattering}

The size and dispersal nature of AuNPs were determined by dynamic light scattering (DLS) particle size analyzer IG-1000 plus (Shimadzu). The sample was mixed with water and sonicated for 20 minutes and assessed.

\section{Fourier-transform infrared spectroscopy}

Sx-AuNPs were analyzed by IRAffinity-1S Fouriertransform infrared spectroscopy (FTIR) spectrophotometer (Shimadzu) in the wavelength range of $400-4,000 \mathrm{~cm}^{-1}$. This instrument offers 30,000:1 ratio, 1-minute accumulation, neighborhood of $2,100 \mathrm{~cm}^{-1}$, and a maximum resolution of $0.5 \mathrm{~cm}^{-1}$. AuNPs were spun and reconstituted in sterile water for purification prior to FTIR analysis.

\section{Transmission electron microscopy and energy- dispersive $\mathrm{X}$-ray analysis}

AuNPs in the sample were analyzed by high-resolutionTEM model Technai G2 (FEI, Hillsboro, OR, USA), and energy-dispersive $\mathrm{X}$-ray (EDX) analysis was also done with transmission electron microscopy (TEM) studies to assure the presence of elemental gold.

\section{Light microscopy}

C666-1 cells were treated with Sx-AuNPs at various concentrations $(5,10$, or $15 \mu \mathrm{g} / \mathrm{mL})$ or using vehicle control $(0.1 \% \mathrm{DMSO})$ and kept in an incubator at $37^{\circ} \mathrm{C}$ for 24 hours, and after the treatment period, the cells were washed once with $1 \times$ PBS. Then, morphological changes of the cells were examined under a phase-contrast microscope at $200 \times$ magnification (Nikon, Tokyo, Japan).

\section{MTT assay}

Cell viability was assayed by the principle of living cells in which yellow MTT is converted into purple formazan crystals by mitochondrial reductases. C666-1 cells were seeded in 24-well plates and exposed to Sx-AuNPs $(0,5$, 10 , or $15 \mu \mathrm{g} / \mathrm{mL}$ ), and then incubated for 24 hours in a $\mathrm{CO}_{2}$ incubator. Another set of cells were pretreated with autophagy inhibitors (3-methyladenine [3-MA], 2/4 mM and chloroquine [CQ], 10/20 $\mu \mathrm{M}$ ) for 1 hour followed by incubation with or without Sx-AuNPs $(10 \mu \mathrm{g} / \mathrm{mL})$ for 24 hours. Then, MTT solution was added, and the mixture was kept at $37^{\circ} \mathrm{C}$ for an hour. The purple-colored formazan crystals formed were then dissolved with DMSO and kept at dark. The color intensity was read at $570 \mathrm{~nm}$ using a microplate reader, and the cell viability was expressed as percentage. Values are expressed as mean $\pm \mathrm{SD}(\mathrm{n}=3)$. Values were considered significant at $* * P<0.01$ and $* * * P<0.001$ compared with untreated control cells, and at ${ }^{\#} P<0.05$ and ${ }^{\#} P<0.01$ compared with Sx-AuNPs-treated cells.

\section{Colony formation assay}

C666-1 cells were seeded and grown in six-well plates at recommended number in duplicates. After reaching 70\% confluency, the cells were treated with Sx-AuNPs at different concentrations $(5,10$, or $15 \mu \mathrm{g} / \mathrm{mL})$ or vehicle control $(0.1 \%$ DMSO) and kept in an incubator at $37^{\circ} \mathrm{C}$ for 7 days (minimum 50 cells/colony). After discarding the medium, the cells were washed once with PBS, and then fixation solution $(2-3 \mathrm{~mL})$ was added and the cells were kept at RT for 5 minutes. After fixation, the cells were stained with crystal violet solution $(0.5 \%)$ and incubated at RT for 2 hours. Then, crystal violet was discarded, cells were washed with tap water, and colonies were counted with a stereomicroscope. ${ }^{27}$ Percentage of colony formation was calculated by defining the number of colonies in the absence of Sx-AuNPs as $100 \%$. Values are expressed as mean $\pm \mathrm{SD}(\mathrm{n}=3)$. Values were considered significant at $* P<0.05, * * P<0.01$, and $* * * P<0.001$ compared with untreated control cells.

\section{Intracellular ROS generation}

C666-1 cells were treated with Sx-AuNPs $(10 \mu \mathrm{g} / \mathrm{mL})$ for $0,5,15$, and 30 minutes. The nonfluorescent cell membranepermeable probe $2^{\prime}-7^{\prime}$-dichlorodihydrofluorescein diacetate (DCFH-DA) $(10 \mu \mathrm{M})$ was added to the culture medium 30 minutes before the end of each experiment. DCFH-DA, which is cell membrane permeable, reacts with cellular ROS and is metabolized into fluorescent $2^{\prime}-7^{\prime}$ dichlorodihydrofluorescein (DCF), acting as an indicator of ROS that was measured by fluorescence microscopy (200x magnification). The intracellular ROS level, as a percentage of the control, is expressed in the graph. Cells were pretreated with the antioxidant $\mathrm{N}$-acetylcysteine (NAC, $5 \mathrm{mM}$ ) for 1 hour followed by incubation with Sx-AuNPs $(0-15 \mu \mathrm{g} / \mathrm{mL})$ for 15 minutes, and intracellular ROS generation was measured using the DCFH-DA fluorescence method. Values 
are expressed as mean $\pm \mathrm{SD}(\mathrm{n}=3)$. Values were considered significant at $* * P<0.01$ and $* * * P<0.001$ compared with untreated control cells, and at ${ }^{\# \#} P<0.001$ compared with Sx-AuNPs-treated cells.

\section{TUNEL assay}

Apoptotic DNA fragmentation was determined by terminal deoxynucleotidyl transferase dUTP nick end labeling (TUNEL) assay. Initially, cells were grown in cover slips and treated with various concentrations of Sx-AuNPs (0-15 $\mu \mathrm{g} / \mathrm{mL}$ ) for 24 hours. In other set, cells were pretreated with caspase inhibitor carbobenzoxy-valyl-alanyl-aspartyl-[Omethyl]- fluoromethylketone (Z-VAD-FMK, $20 \mu \mathrm{M})$ or NAC $(5 \mathrm{mM})$ for 1 hour followed by incubation with or without SxAuNPs $(15 \mu \mathrm{g} / \mathrm{mL})$. Cells were fixed with $1 \%$ formaldehyde in PBS for 15 minutes. Then, cells were washed with ice-cold $70 \%$ ethanol for an hour. After that, $50 \mu \mathrm{L}$ of terminal deoxynucleotidyl transferase (TdT) buffer was added, and cells were incubated at $37^{\circ} \mathrm{C}$ for half an hour. The cells were washed once with PBS and then incubated with TdT staining buffer for 30 minutes at RT in dark. The cells were finally washed with PBS and observed under a confocal microscope. The green fluorescence indicates TUNEL-positive cells in the microscopic fields (200× magnification) from three separate samples.

\section{Western blotting}

C666-1 cells were treated with Sx-AuNPs at different concentrations and lysed with lysis buffer containing phosphatase and protease inhibitors. After protein estimation, equal concentrations of protein were loaded in SDS-PAGE gel and resolved. The separate proteins were blotted onto a membrane, blocked with 5\% blocking buffer, and incubated with primary antibodies specific for procaspase-9, procaspase-3, PARP, Bax, Bcl-2, LC3-I/II, p-mTOR, mTOR, ATG7, P62/ SQSTM1, and ATG4B overnight (1:2,000 dilution). After washing the membranes with tris-buffered saline, the membranes were incubated with respective secondary antibodies conjugated with horse radish peroxidase. The proteins were identified using an enhanced chemiluminescence (ECL) substrate, imaged, and quantified by ChemiDoc XRS system - Quantity One software (BioRad, Hercules, CA, USA). $\beta$-Actin was used as loading control. Relative changes in the ratio of $\mathrm{Bax} / \mathrm{Bcl}-2$ in accordance with the dose were measured by commercially available quantitative software, with the control representing one-fold. Values are expressed as mean $\pm \mathrm{SD}(\mathrm{n}=3)$. Values were considered significant at $* P<0.05$ and $* * * P<0.001$ compared with untreated control cells.

\section{Acridine orange staining}

C666-1 cells were grown till they reached the required confluence, and then they were treated with or without Sx-AuNPs at various concentrations $(2.5,5,7.5$, and $10 \mu \mathrm{g} / \mathrm{mL})$ for 24 hours. After washing the cells with $1 \times$ PBS twice, $500 \mu \mathrm{L}$ of acridine orange was added, and the cells were visualized under a red filter fluorescence microscope for development of acidic vesicular organelles (AVOs).

\section{Statistical analysis}

Data are represented as mean and standard error (SE) from experiments performed in triplicate. Statistical significance was evaluated by a two-sided Student's $t$-test. A value of $P<0.05$ was considered significant.

\section{Results \\ UV-visible spectrum absorption pattern of AuNPs synthesized from Sx}

UV-visible absorption spectroscopy was used to study the stability of metal nanoparticles. The UV-visible absorption spectrum of AuNPs synthesized from Sx is shown in Figure 1A. The samples used were obtained from day 1 (24 hours) to day 30. All the samples showed two absorption peaks (one higher and one shorter). In a day 30 sample, there was a decrease in the absorbance in peak 1 , while there was an increase in peak 2 when compared with other three samples. There was a significant shift in the absorbance from day 1 to day 30 with $\lambda_{\text {max }}$ at $525 \mathrm{~nm}$ (this study focused on the absorption peak at around $500 \mathrm{~nm}$ ). This may be due to increased formation of AuNPs with size reduction and the color change (wine red color). A visible color change was also observed when compared with the control in the presence of AuNPs (Figure 1B). These results clearly indicate the formation of AuNPs from the Sx extract.

\section{XRD pattern and DLS analysis of AuNPs synthesized from Sx}

XRD of AuNPs synthesized from the Sx plant extract showed the pattern corresponding to AuNPs reflecting their nanostructures. AuNPs showed some peaks with a single-intense diffraction (approximately 40) corresponding to Bragg reflections of cubic face-centered cubic lattice. These XRD data showed typical, pure AuNPs formation (Figure 2A). DLS technique is used for the measurement of particle size in a suspension. According to the Rayleigh scattering principle, small-sized particles involve in light scattering in all directions. From the DLS result, it was clear that cumula- 

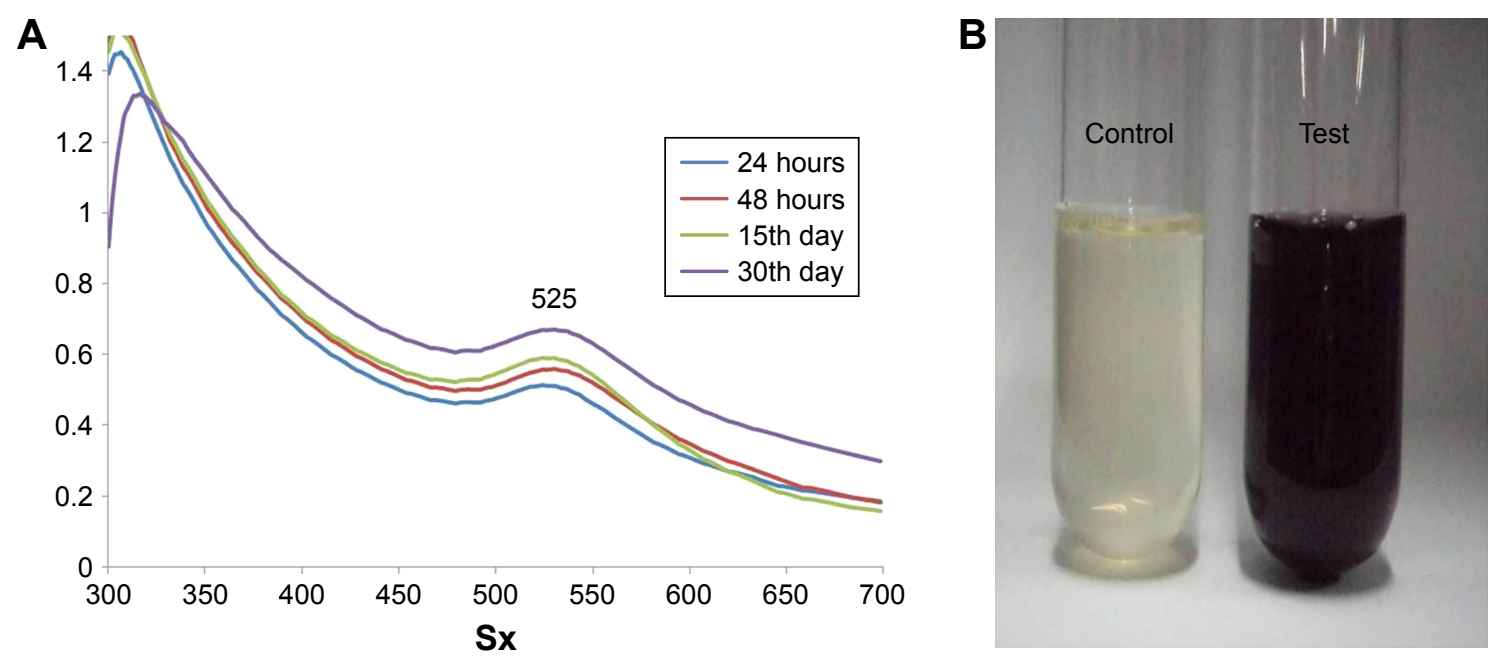

Figure I UV-visible spectrum absorption pattern of AuNPs synthesized from Sx.

Abbreviations: AuNPs, gold nanoparticles; Sx, Solanum xanthocarpum.

tive distribution frequency that showed $94.3 \%$ of particles present in the suspension were of an average diameter of $142 \mathrm{~nm}$ (Figure 2B).

\section{FTIR analysis of AuNPs synthesized from Sx}

FTIR analyses of AuNPs formed from Sx were performed in the wave number range of $400-4,000 \mathrm{~cm}^{-1}$. Figure 3 shows the presence of various chemical groups and FTIR signals of AuNPs obtained from Sx corresponding to $\mathrm{CH}$ stretching of alkanes $\left(2,931\right.$ and 2,097 $\left.\mathrm{cm}^{-1}\right), \mathrm{C}=\mathrm{O}$ stretching vibration of carbonyl $\left(1,750 \mathrm{~cm}^{-1}\right), \mathrm{CH}$ or $=\mathrm{CH}-\mathrm{H}$ stretching $\left(1,407 \mathrm{~cm}^{-1}\right), \mathrm{C}-\mathrm{O}$ stretching $\left(1,014 \mathrm{~cm}^{-1}\right)$, and aromatic $\mathrm{CH}$ bending $\left(817 \mathrm{~cm}^{-1}\right)$. These groups suggest the presence of AuNPs. ${ }^{28,29}$

\section{TEM and EDX analysis of AuNPs synthesized from Sx}

TEM imaging uses a narrow beam of electrons focused on the sample and measures the size of the particle accurately. TEM images showed AuNPs as dark spots against a light background. TEM micrographs of AuNPs are shown in Figure 4A. AuNPs are seen clearly with a size of around $100 \mathrm{~nm}$. To confirm the presence of gold in the sample,
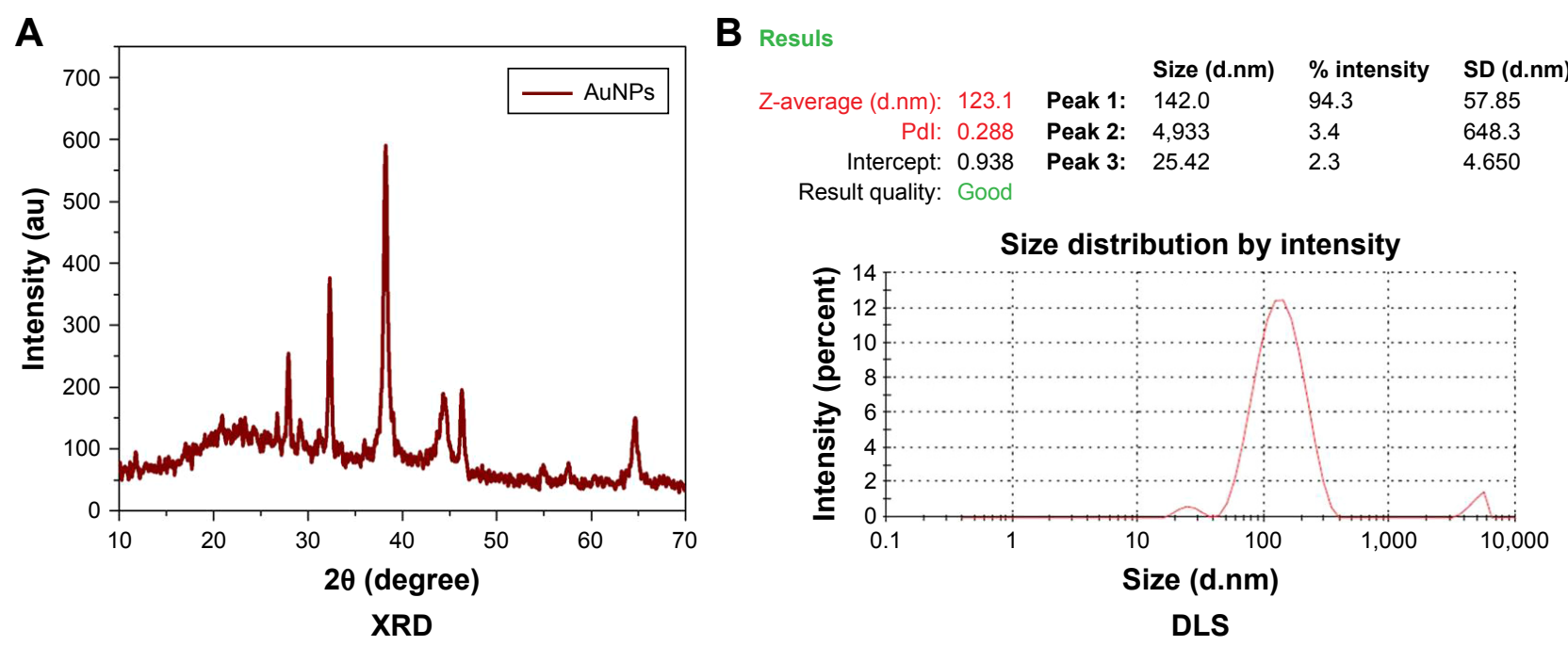

Figure 2 XRD pattern and DLS analysis of AuNPs synthesized from Sx.

Abbreviations: DLS, dynamic light scattering; AuNPs, gold nanoparticles; Sx, Solanum xanthocarpum; XRD, X-ray Diffraction. 


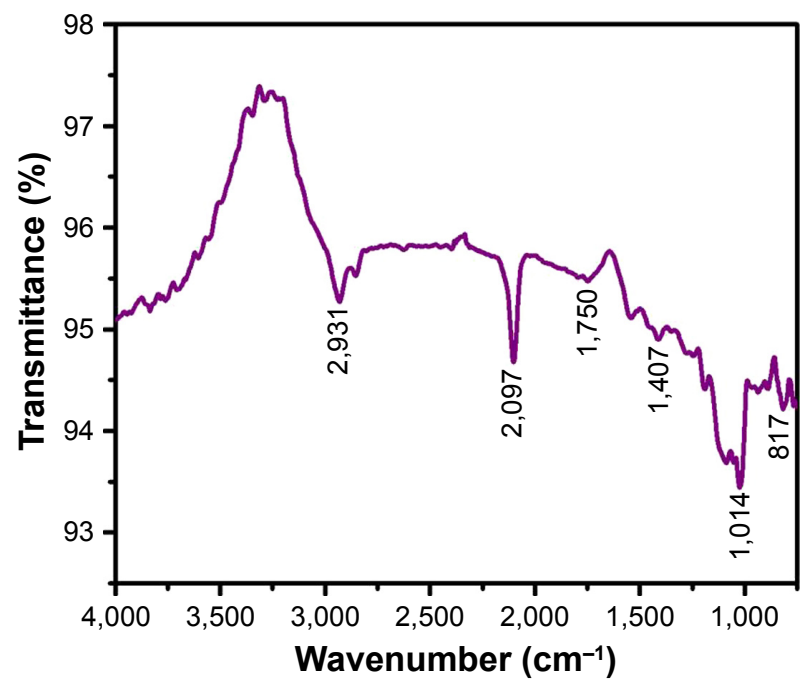

Figure 3 FTIR analysis of AuNPs synthesized from Sx.

Abbreviations: FTIR, Fourier-transform infrared spectroscopy; AuNPs, gold nanoparticles; Sx, Solanum xanthocarpum.

EDX analysis was performed, which showed sharp intense optical absorption peaks that depicted typical metal gold nanocrystallites (Figure 4B).

\section{Sx-AuNPs inhibit viability and colony formation of NPC (C666-I) cells} microscopic observations. Control cells showed normal morphology of C666-1 cells (100\% viability), which upon treatment with Sx-AuNPs showed a rounded morphology and a decline in colony formation at $15 \mu \mathrm{g} / \mathrm{mL}$ concentration (Figure 5A). Colony formation assay was performed cells. In comparison with control cells that formed several colonies (considered as 100\%), treatment with Sx-AuNPs
Viability of cells was assessed by MTT assay and light to find the long-term consequence of Sx-AuNPs on C666-1

decreased the formation of colonies at 5,10 , and $15 \mu \mathrm{g} / \mathrm{mL}$ concentration with maximum effect observed at $15 \mu \mathrm{g} / \mathrm{mL}$ (only 20\% colony formation; Figure 5B).

\section{Sx-AuNPs induce intracellular ROS generation in C666-I cells}

ROS generation was analyzed by probing DCFH-DA and measured by fluorescence microscopy. When compared with control cells, treatment with Sx-AuNPs $(10 \mu \mathrm{g} / \mathrm{mL})$ increased the generation of ROS by 5 minutes (eight-fold), and maximal effect was observed at 15 minutes (ten-fold). This effect was not observed at 30 minutes (Figure 6A). The intracellular ROS level, as a percentage of the control, is expressed in the graph (Figure 6B). When C666-1 cells were treated with Sx-AuNPs $(0-15 \mu \mathrm{g} / \mathrm{mL})$ for 15 minutes, ROS generation increased in a dose-dependent manner (maximum to 20-fold), while NAC pretreatment for 1 hour followed by incubation with Sx-AuNPs $(15 \mu \mathrm{g} / \mathrm{mL})$ completely abolished the generation of ROS (Figure 6C and D).

\section{Sx-AuNPs trigger apoptotic DNA fragmentation through activation of mitochondrial pathways in C666-I cells}

Apoptosis was analyzed by TUNEL assay. The green fluorescence indicates TUNEL-positive cells in the microscopic fields (200× magnification) from three separate samples. In control cells, there were no TUNEL-positive cells, while treatment with $\mathrm{Sx}$-AuNPs increased the number of apoptotic cells in a dose-dependent manner. DAPI was used to stain nuclei, and nuclear fragmentation resulted in a decrease in blue fluorescence observed in the second panel of Figure 7A. Third panel shows the merge image of green and blue

B

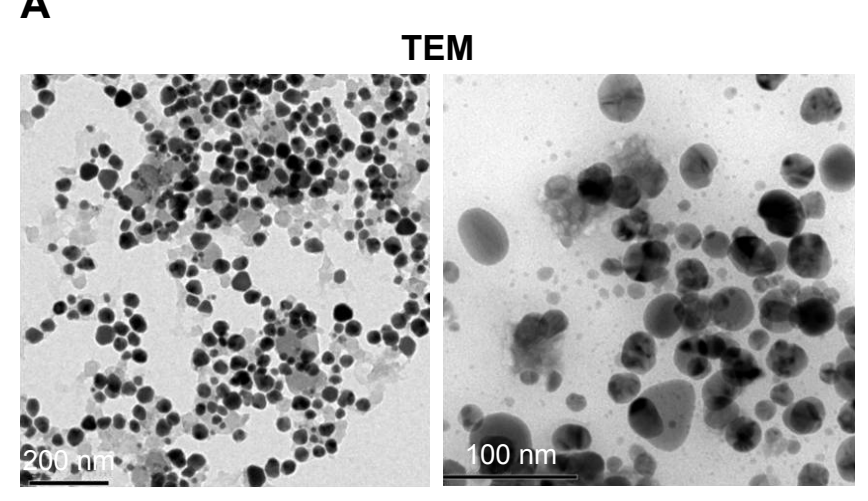

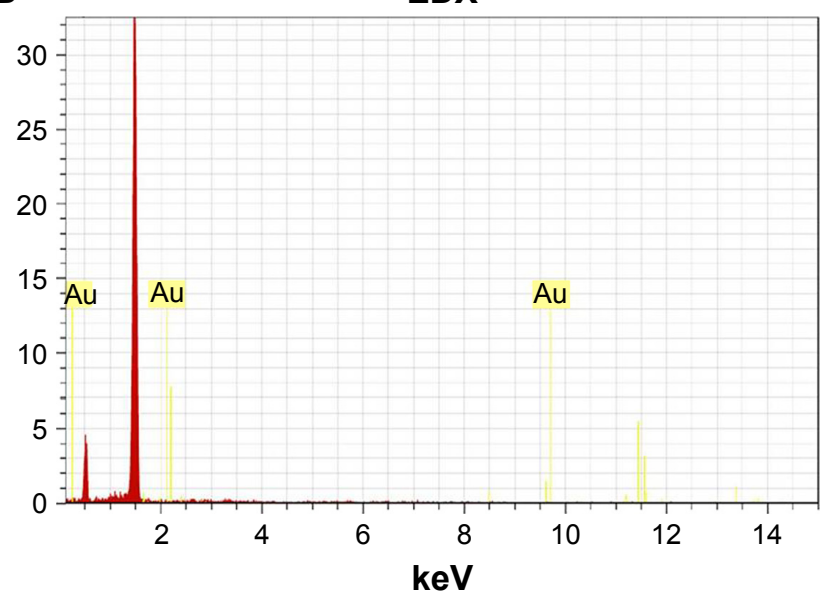

Figure 4 (A) TEM and (B) EDX analysis of AuNPs synthesized from Sx.

Abbreviations: EDX, energy-dispersive X-ray analysis; TEM, transmission electron microscopy; AuNPs, gold nanoparticles; Sx, Solanum xanthocarpum. 
A

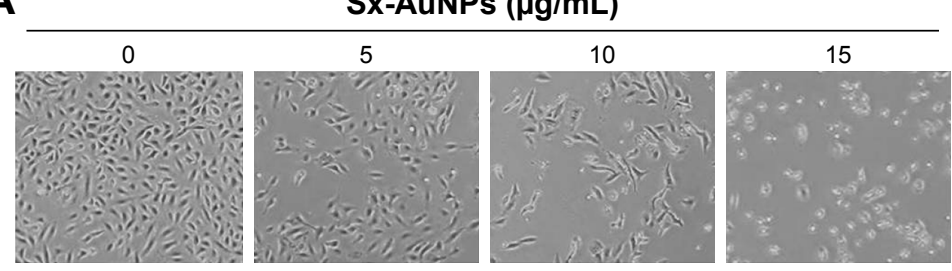

B

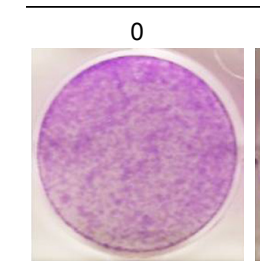

Sx-AuNPs $(\mu \mathrm{g} / \mathrm{mL})$

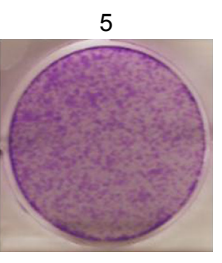

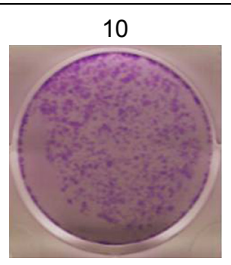

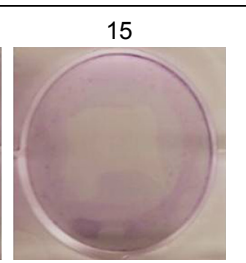

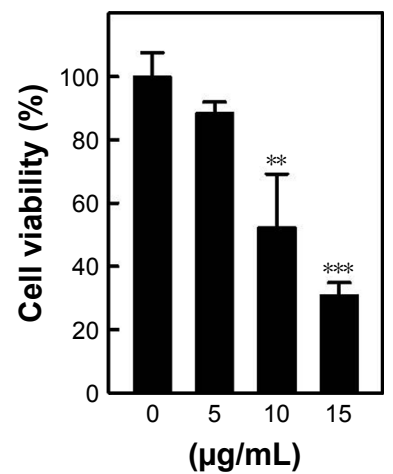

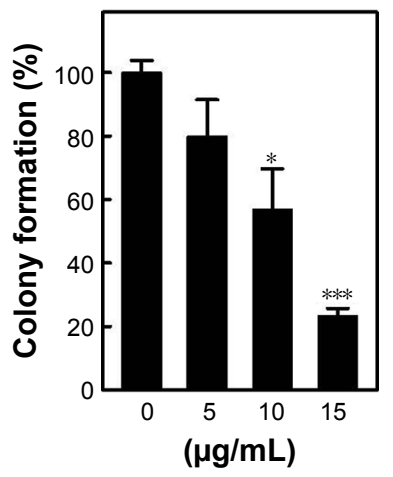

Figure 5 Sx-AuNPs inhibit viability and colony formation of nasopharyngeal carcinoma (C666-I) cells.

Notes: (A and B) Cells were treated with various concentrations of Sx-AuNPs (5-15 $\mu \mathrm{g} / \mathrm{mL})$ for 24 hours or with vehicle control ( $0.1 \%$ DMSO), and morphological changes were examined under a phase-contrast microscope (200x magnification). Cell viability was determined using the MTT assay. Cells were incubated with Sx-AuNPs ( 0 , 5 , 10 , and $15 \mu \mathrm{g} / \mathrm{mL}$ ) for 7 days, and the percentage of colony formation was calculated by defining the number of colonies in the absence of Sx-AuNPs as $100 \%$. Values are expressed as mean $\pm S D(n=3)$. Values were considered significant at $* P<0.05$, $* * P<0.0$ I, and $* * * P<0.00$ I compared with untreated control cells.

Abbreviations: AuNP, gold nanoparticle; DMSO, dimethyl sulfoxide; Sx, Solanum xanthocarpum.

fluorescence. The fold of apoptotic cells was calculated by measuring the fluorescence intensity of treated cells using commercially available software (Figure 7B). Paclitaxel $(20 \mu \mathrm{g} / \mathrm{mL})$ was used as a positive control.

Expression of proteins involved in apoptotic machinery was analyzed by Western blotting (Figure 7C). In C666-1 control cells, there was no caspase cleavage observed significantly. However, treatment with Sx-AuNPs (5, 10, or $15 \mu \mathrm{g} / \mathrm{mL}$ ) induced caspase-9 cleavage from procaspase- 9 . A similar pattern was observed in caspase-3 and poly (ADP-ribose) polymerase (PARP) cleavage. The expression of proapoptotic protein (Bax) was minimal in C666-1 cells, which increased upon treatment with Sx-AuNPs with maximum effect observed at $15 \mu \mathrm{g} / \mathrm{mL}$ concentration. Moreover, the expression of Bcl-2 (antiapoptotic protein) declined over treatment with Sx-AuNPs in a dosedependent manner. $\beta$-Actin in the lower panel was used as a loading control.

\section{Sx-AuNPs-induced ROS generation is involved in C666-I cell apoptosis}

Oxidative stress is one of the chief causes for induction of apoptosis. Hence, to analyze the ROS generation, cells were pretreated with a caspase inhibitor (Z-VAD-FMK) or an antioxidant (NAC), and then treated with Sx-AuNPs at a concentration of $15 \mu \mathrm{g} / \mathrm{mL}$. Sx-AuNP treatment caused a significant increase in TUNEL-positive cells, indicating apoptosis of C666-1 cells. In contrast, this increase was inhibited by both caspase inhibitor (Z-VAD-FMK) and antioxidant (NAC; Figure 8A). This result is schematically represented in Figure $8 \mathrm{~B}$. These results were supported by cell viability assay, which showed a significant decrease in viability of C666-1 cells upon treatment with $15 \mu \mathrm{g} / \mathrm{mL}$ Sx-AuNPs, whereas this increased upon exposure to caspase inhibitor (Z-VAD-FMK) and antioxidant (NAC; Figure 8C). These data clearly manifest that $\mathrm{Sx}$-AuNP-induced apoptosis is mediated by generation of ROS.

\section{Sx-AuNPs trigger autophagy signaling molecules in C666-I cells}

Expression of autophagy signaling molecules was analyzed by Western blotting. LC3-I/II showed a steady and dosedependent increase upon treatment with Sx-AuNPs at various concentrations $(2.5-10 \mu \mathrm{g} / \mathrm{mL})$. A similar pattern was also noted in the expression of ATG7. On the other hand, Sx-AuNP treatment decreased the phosphorylation 
A

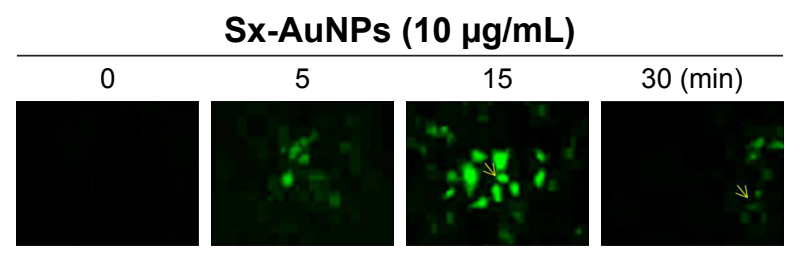

C

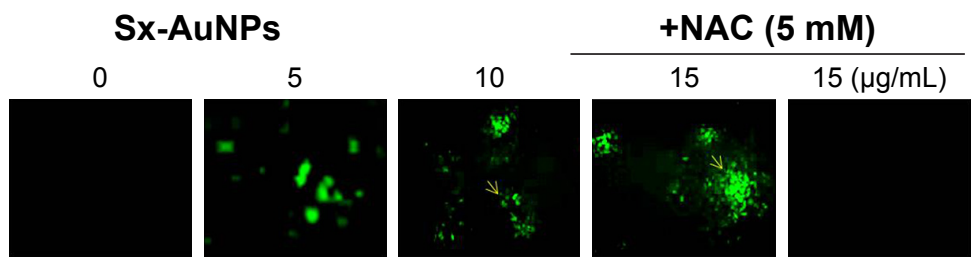

B
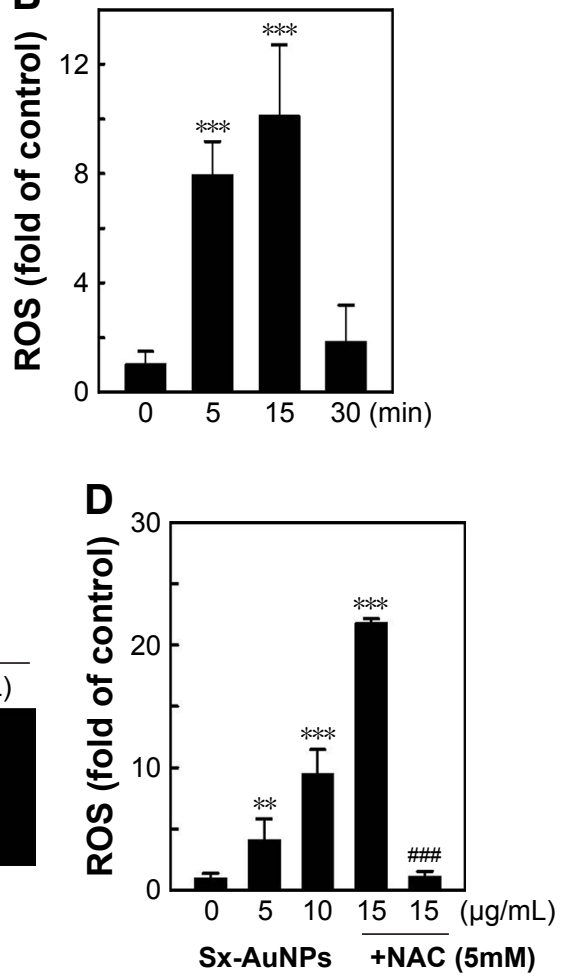

Figure 6 Sx-AuNPs induce intracellular ROS generation in C666-I cells.

Notes: (A and B) Cells were treated with Sx-AuNPs $(10 \mu \mathrm{g} / \mathrm{mL})$ for $0,5,15$, and 30 minutes. The nonfluorescent cell membrane-permeable probe DCFH-DA (I0 $\mu$ M) was added to the culture medium 30 minutes before the end of each experiment. DCFH-DA, which is cell membrane permeable, reacts with cellular ROS and is metabolized into fluorescent DCF, acting as an indicator of ROS that was measured by fluorescence microscopy (200× magnification). The intracellular ROS level, as a percentage of the control, is expressed in the graph. (C and D) Cells were pretreated with the antioxidant NAC (5 mM) for I hour followed by incubation with Sx-AuNPs (0-15 $\mu$ g/mL) for 15 minutes, and intracellular ROS generation was measured using the DCFH-DA fluorescence method. Values are expressed as mean \pm SD ( $\mathrm{n}=3$ ). Values were considered significant at $* * P<0.01$ and $* * * P<0.001$ compared with untreated control cells and ${ }^{\prime \prime} P<0.001$ compared with Sx-AuNPs-treated cells.

Abbreviations: AuNP, gold nanoparticle; DCF, 2'-7'-dichlorodihydrofluorescein; DCFH-DA, 2'-7'-dichlorodihydrofluorescein diacetate; NAC, N-acetylcysteine; Sx, Solanum xanthocarpum.

of mTOR and expression of mTOR, P62/SQSTM1, and ATG4B in C666-1 cells (Figure 9). $\beta$-Actin was used as a loading control.

\section{Induction of autophagy in C666-I cells by Sx-AuNPs treatment}

Autophagy is assessed by AO, which emits red fluorescence in acidic milieu. Moreover, AO detects all AVOs. When compared with control cells, Sx-AuNPs treatment (2.5-10 $\mu \mathrm{g} / \mathrm{mL})$ for 24 hours increased AVOs in C666-1 cells in a dose-dependent pattern (Figure 10A). These data are graphically represented in Figure 10B and C. The cell viability was also analyzed by MTT assay, which showed $100 \%$ cell viability in control cells. Sx-AuNPs $(10 \mu \mathrm{g} / \mathrm{mL})$ decreased cell viability to nearly $50 \%$. This decrease in viability was augmented by treatment with autophagy inhibitors (either 3-MA or CQ). This clearly showed that decrease in cell viability observed upon treatment with Sx-AuNPs is due to autophagy.

\section{Discussion}

Conventionally, the production of nanoparticles was carried out by means of different methods that employ hazardous chemicals, and they were quite expensive. Recent research has focused on green synthesis of nanoparticles, where extracts of plants or their products are used as reducing or stabilizing agents. There are enormous phytochemicals that act as reducing agents and hence provide a novel and safe approach for synthesizing nanoparticles. Of all the nanoparticles, AuNPs have gained much interest because of their superior physical, chemical, and mechanical properties which have made them the most studied entities during recent years in cancer diagnostics. ${ }^{30,31}$ The most promising applications of AuNPs in cancer are fluoroimmunoassay, multiplex diagnosis, tumor detection, and molecular imaging. The immense potential of AuNPs would shed light on various applications in cancer research. The presence of six free electrons in AuNPs allows them to bind with amines and thiols and to easily bind with macromolecules. ${ }^{32}$ Various plant species have been used so 


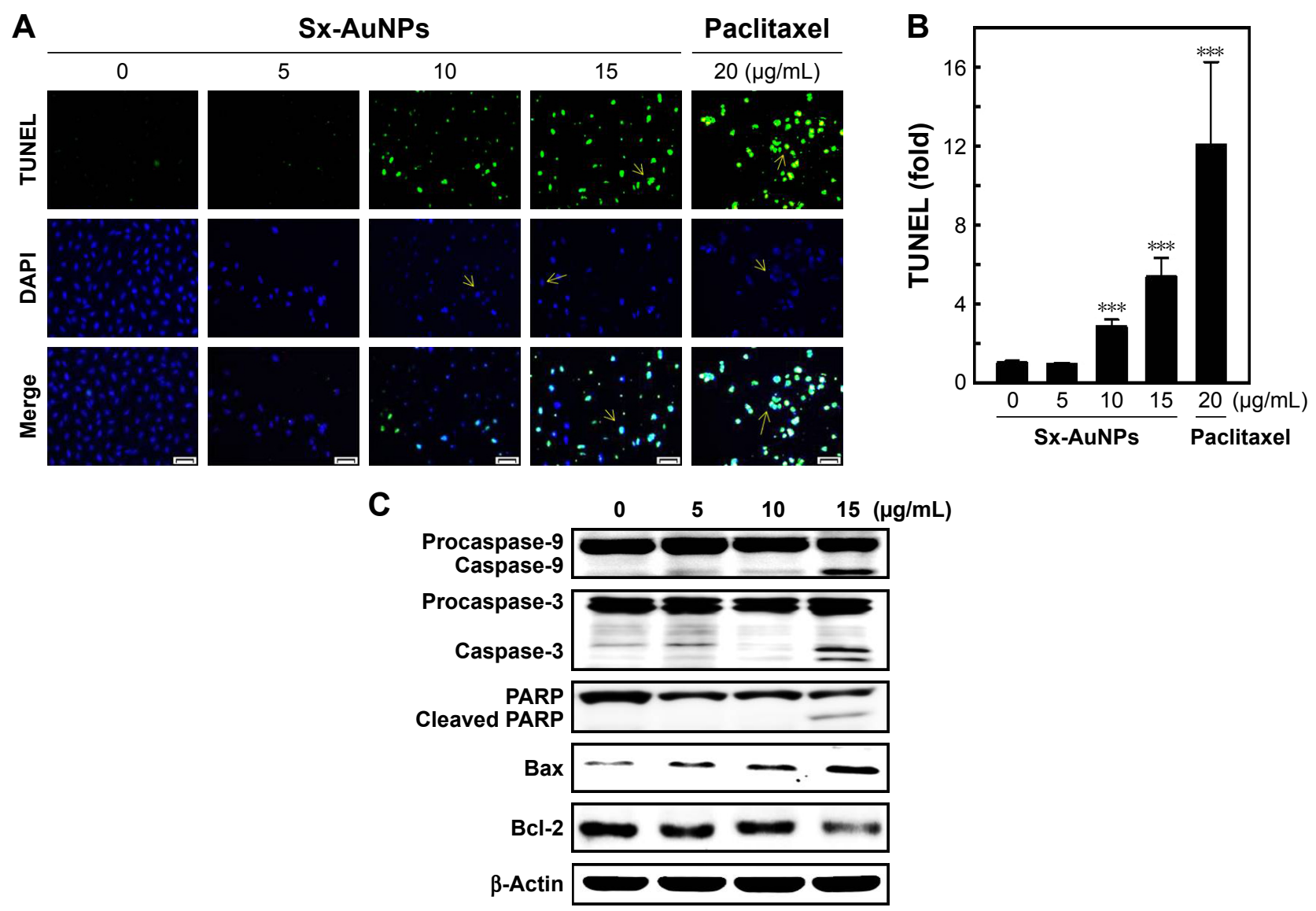

Figure 7 Sx-AuNPs trigger apoptotic DNA fragmentation through activation of mitochondrial pathways in C666-I cells. Cells were treated with various concentrations of Sx-AuNPs $(0-15 \mu \mathrm{g} / \mathrm{mL})$ for 24 hours.

Notes: (A) Apoptotic DNA fragmentation was determined by TUNEL assay. The green fluorescence indicates TUNEL-positive cells in the microscopic fields (200X magnification) from three separate samples. (B) The fold of apoptotic cells was calculated by measuring the fluorescence intensity of treated cells using commercially available software. Paclitaxel $(20 \mu \mathrm{g} / \mathrm{mL})$ was used as a positive control. Cells were treated with various concentrations of Sx-AuNPs (0-15 $\mu g / \mathrm{mL})$ for 24 hours. (C) Changes in protein levels of procaspase-9, caspase-9, procaspse-3, caspase-3, and PARP were estimated by Western blotting. $\beta$-Actin was used as a loading control. Sx-AuNPs increased the ratio of Bax/Bcl-2. Dose-dependent $(0-15 \mu \mathrm{g} / \mathrm{mL})$ effects of Sx-AuNPs on changes in Bax and Bcl-2 proteins were determined by Western blotting. Relative changes in the ratio of $\mathrm{Bax} / \mathrm{Bcl}-2$ in accordance with the dose were measured by commercially available quantitative software with the control representing onefold. Values are expressed as mean $\pm S D(n=3)$. Values were considered significant at $* * * P<0.001$ compared with untreated control cells.

Abbreviations: AuNP, gold nanoparticle; Sx, Solanum xanthocarpum.

far for AuNP synthesis. Sx is a traditionally used herb for various maladies such as allergy, and GI, heart, and lung diseases.

In the present study, AuNPs were synthesized from Sx leaf extracts, and the synthesized AuNPs were characterized by techniques such as XRD, FTIR, DLS, and TEM. As evident from UV-visible absorption spectroscopy, there was a shift in the wavelength with $\lambda_{\text {max }}$ at $525 \mathrm{~nm}$ and a visible color change to wine red was noted by day 30 , which are the exact characteristics of the presence of AuNPs. Similarly, XRD and DLS analyses showed the presence of nanoparticles with an average diameter of $142 \mathrm{~nm}$ satisfying the criterion of a nanoparticle. FTIR analyses of the samples showed the presence of various functional groups such as $\mathrm{C}=\mathrm{O}, \mathrm{CH}$, aromatic, $\mathrm{CH}$, and $\mathrm{C}-\mathrm{O}$. TEM and EDX data also confirmed the presence of typical metal gold nanocrystallites.
The synthesized Sx-AuNPs were analyzed for their anticarcinogenic potential in NPC cell line, C666-1. Sx-AuNPs decreased the viability of C666-1 cells, as well as significantly suppressed their colony-forming ability at concentrations of 5,10 , and $15 \mu \mathrm{g} / \mathrm{mL}$. Similar to this study, it was shown that treatment of MCF-7 cells with gold nanorods at $2.5 \mu \mathrm{g} / \mathrm{mL}$ concentration decreased the viability of cells to $54 \% .^{33}$ Rajeshkumar $^{34}$ showed that AuNPs $(100 \mu \mathrm{g})$ reduced the viability of liver cancer (HepG2) and lung cancer (A549) cell lines. Similarly, AuNPs were found to be cytotoxic to ovarian cancer cells in vitro (OVCAR5, OVCAR8, SKOV3). ${ }^{35}$ Another study also confirmed that AuNPs reduced the viability of HeLa cells with $\mathrm{IC}_{50}$ value obtained at $100 \mu \mathrm{g} / \mathrm{mL}$ concentration, while for bone marrow stem cells the $\mathrm{IC}_{50}$ value was $300 \mu \mathrm{g} / \mathrm{mL} .{ }^{36}$ Suppression in cell viability (69\%) was observed in MCF-7 cells upon treatment with AuNPs at $200 \mu \mathrm{g} / \mathrm{mL} .{ }^{37}$ 
A
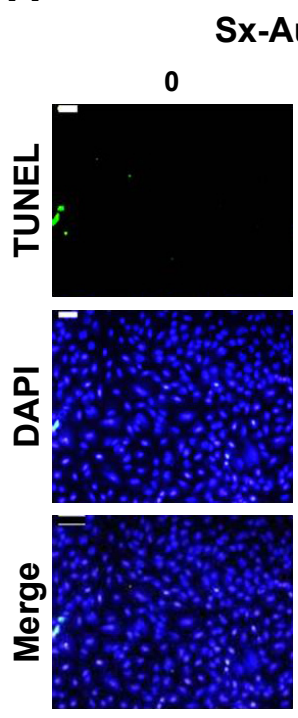

+Z-VAD FMK (20 mM)

15
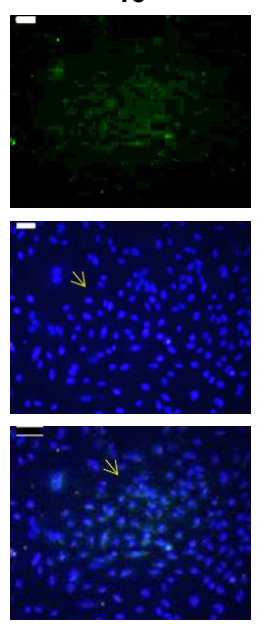

+NAC (5 mM) $15(\mu \mathrm{g} / \mathrm{mL})$
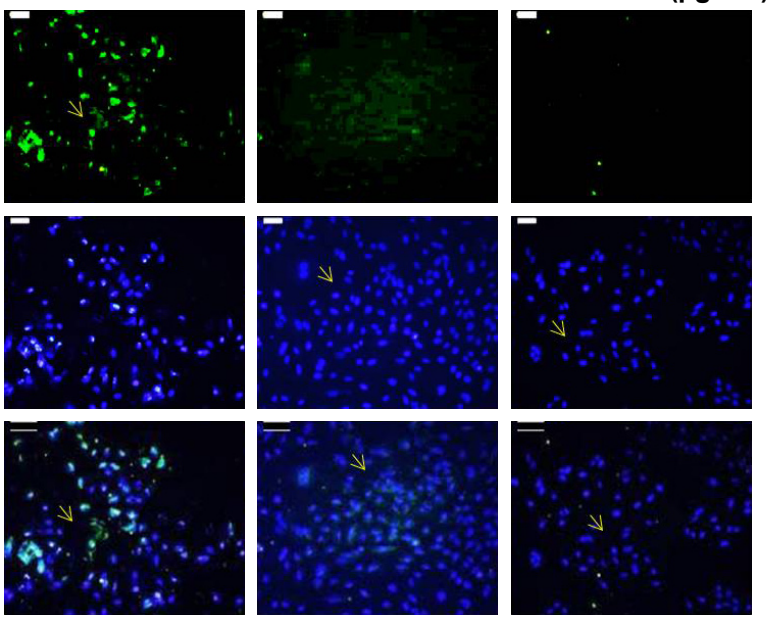

Figure 8 Sx-AuNPs-induced ROS generation is involved in C666-I cell apoptosis. Cells were pretreated with caspase inhibitor (Z-VAD-FMK, $20 \mu$ M) or NAC (5 mM) for I hour followed by incubation with or without Sx-AuNPs (I5 $\mu \mathrm{g} / \mathrm{mL})$.

Notes: (A) Apoptotic DNA fragmentation was determined by TUNEL assay. The green fluorescence indicates TUNEL-positive cells in the microscopic fields (200x magnification) from three separate samples. (B) The fold of apoptotic cells was calculated by measuring the fluorescence intensity of the treated cells using commercially available software. (C) The cell viability was determined by the MTT assay. Values are expressed as mean \pm SD ( $=3$ ). Values were considered significant at $* * * P<0.00$ I compared with untreated control, and ${ }^{\#}<0.01$ and ${ }^{\#} P<0.001$ compared with Sx-AuNPs-treated cells.

Abbreviations: AuNP, gold nanoparticle; NAC, N-acetylcysteine; Sx, Solanum xanthocarpum.

A

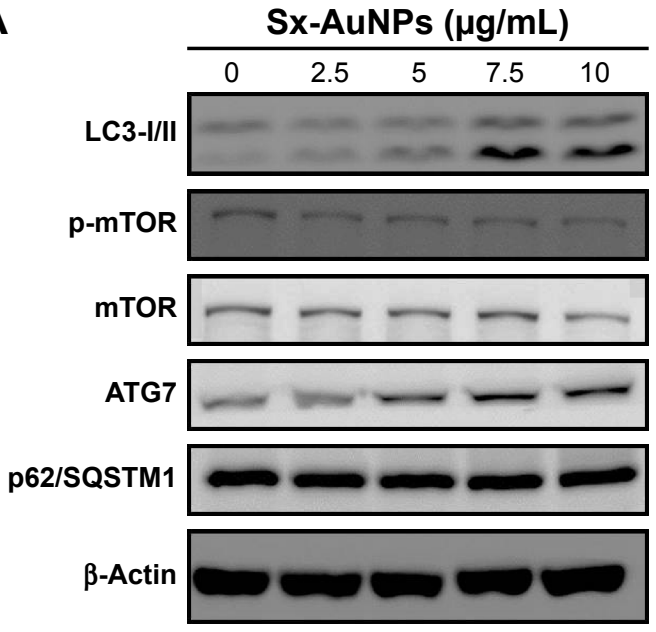

B

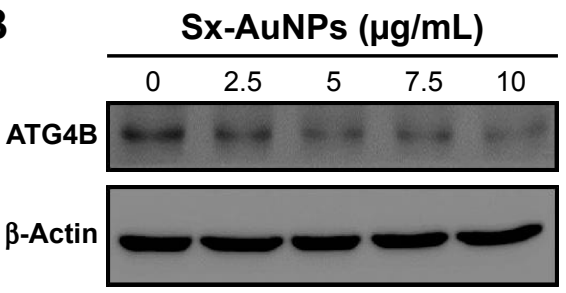

Figure 9 Sx-AuNPs trigger autophagy signaling molecules in C666-I cells.

Notes: (A) Cells were treated with Sx-AuNPs $(0-10 \mu \mathrm{M})$ for 24 hours, and then conversion of LC3-I to LC3-II was determined by Western blotting. Dose-dependent changes in the expressions of p-mTOR, mTOR, p62/SQSTMI, and ATG7 in response to Sx-AuNPs were monitored by Western blotting. $\beta$-Actin was used as a loading control. (B) Sx-AuNPs inhibited ATG4B protein levels.

Abbreviations: AuNP, gold nanoparticle; Sx, Solanum xanthocarpum. 


\section{A}

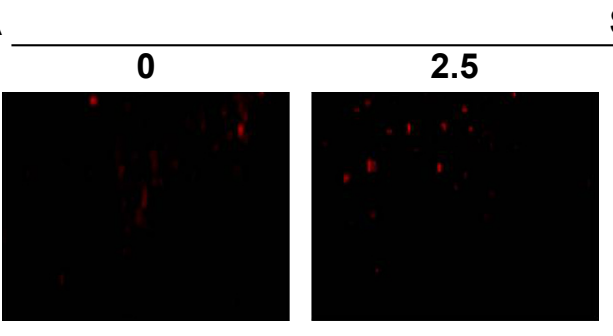

Sx-AuNPs $(\mu \mathrm{g} / \mathrm{mL})$

B

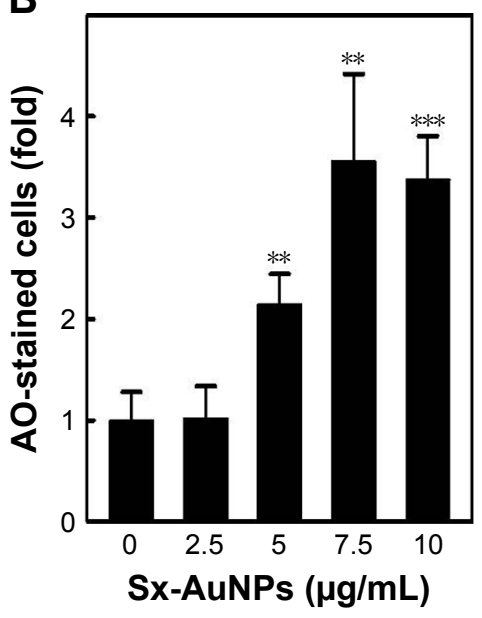

C

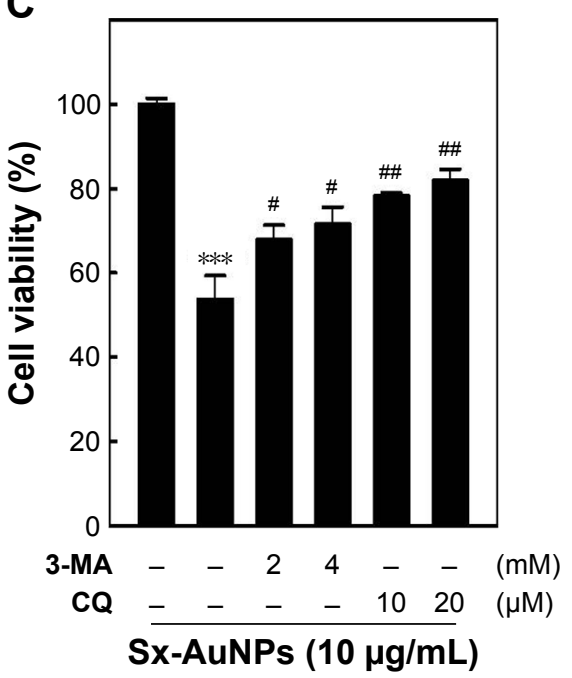

Figure 10 Induction of autophagy in C666-I cells by Sx-AuNPs treatment.

Notes: (A) Cells were treated with various concentrations of Sx-AuNPs $(0-10 \mu g / \mathrm{mL})$ for 24 hours. Cells were stained with AO for AVO observation in untreated or Sx-AuNPs-treated cells. (B) The cells were visualized under a red filter fluorescence microscope. The fold cells developed AVOs. (C) Cells were pretreated with autophagy inhibitors (3-MA, $2 / 4 \mathrm{mM}$ and CQ, $10 / 20 \mu \mathrm{M})$ for I hour followed by incubation with or without Sx-AuNPs (10 $\mu \mathrm{g} / \mathrm{mL})$ for 24 hours. Cell viability was analyzed by the MTT assay. Values are expressed as mean $\pm S D(n=3)$. Values were considered significant at $* * P<0.01$ and $* * * P<0.001$ compared with untreated control cells, and ${ }^{\#} P<0.05$ and \# $P$ < 0 .0 I compared with Sx-AuNPs-treated cells.

Abbreviations: 3-MA, 3-methyladenine; AO, acridine orange; AuNP, gold nanoparticle; AVO, acidic vesicular organelle; CQ, chloroquine; Sx, Solanum xanthocarpum.

Generation of ROS is a critical event in causing aging or senescence and apoptosis. ${ }^{38}$ ROS include superoxide ions, hydroxyl radicals, $\mathrm{H}_{2} \mathrm{O}_{2}$, singlet oxygen, and so on. ${ }^{39}$ Overproduction of ROS results eventually in oxidative stress which, in turn, leads to lipid peroxidation, duplex DNA breaks, genotoxicity, and apoptosis. ${ }^{40,41}$ In this study, Sx-AuNPs increased the generation of ROS in C666-1 cells, which was prevented by an antioxidant, NAC. This clearly showed that apoptosis induced by Sx-AuNPs is through ROS generation. Several studies showed that metal nanoparticles enhanced ROS generation and induced oxidative stress and DNA damage in various cancer cell lines. ${ }^{42}$

A normal physiological process of self-digestion of cell organelles in response to starvation, stress, repair, and apoptosis is termed as "autophagy". LC3 is a soluble protein that exists in two forms: LC3-I (cytosolic form) and LC3-II (autophagosomal membrane-tethered form). LC3-II is used as a marker of autophagosome formation, and its expression indicates autophagic cell death. ${ }^{43}$ In this study, Sx-AuNPs increased the expression of LC3-I/II levels, showing that cell death was due to autophagy. Similar to this, ATG7, which acts as an E1-like activating enzyme, is also involved in autophagy, and the level of this protein also increased upon exposure to Sx-AuNPs. Consistent with the findings, AuNPs treatment of lung fibroblasts increased LC3 and ATG7 proteins. ${ }^{44}$ Autophagy induction by starvation is through inhibiting TOR, and hence, there exists a strong correlation between mTOR and autophagy. In this study, there was a decrease in the phosphorylation of mTOR, which showed an increase in autophagy. p62 levels are used as a reporter of autophagy and showed a slight decrease upon treatment with Sx-AuNPs.

The cell death induced by Sx-AuNPs can be due to either necrosis or apoptosis. To confirm the cell death by apoptosis, TUNEL assay was performed, which showed clear fragmentation of nuclei, a hallmark of apoptosis. On the other hand, proteins involved in apoptotic machinery were also assessed by Western blotting. To maintain normal cell survival, there should a balance between proapoptotic protein Bax and antiapoptotic protein Bcl-2. Sx-AuNPs treatment altered the Bax/ 
Bcl-2 ratio and activated caspase- 3 and caspase-9, thereby inducing apoptosis. AuNPs exposure of HeLa cells showed an increase in caspase- 3 and caspase- 9 activation. ${ }^{36}$ AuNPs upregulated mRNA expression of p53, Bax, caspase-3, and caspase-9, while they downregulated the expression of antiapoptotic Bcl-2 mRNA in MCF-7 cells. ${ }^{37}$

Exposure to AuNPs caused nuclear condensation and formation of apoptotic bodies in HeLa cells. Moreover, treatment of HeLa cells with AuNPs at $100 \mu \mathrm{g} / \mathrm{mL}$ concentration showed late apoptotic cells displaying chromatin clumping and condensation exhibited on AO staining (orange). ${ }^{36} \mathrm{DNA}$ staining by propidium iodide in MCF-7 cells after treatment with AuNPs showed rounded appearance of cells, chromatin condensation, and DNA fragmentation. ${ }^{37}$

Moreover, the formation of AVO is a key event in the process of autophagy which can be seen as red staining by protonated AO. Sx-AuNPs induced the formation of AVOs in C666-1 cells, which was prevented by autophagy inhibitors, 3-MA and CQ.

\section{Conclusion}

It was clear that Sx-AuNPs suppressed the viability and colony formation of NPC cells (C666-1) by inducing autophagy and apoptosis. This was accompanied by activation of caspase- 3 and caspase-9, nuclear fragmentation, and altered autophagy machinery. Thus, AuNPs synthesized from Sx plant extract displayed potential anticarcinogenic ability and could be studied extensively in future for applications in clinical perspective.

\section{Disclosure}

The authors report no conflicts of interest in this work.

\section{References}

1. Jia WH, Qin HD. Non-viral environmental risk factors for nasopharyngeal carcinoma: a systematic review. In: Seminars in Cancer Biology (Vol 22, No 2, pp 117-126). Academic Press; 2012.

2. Lozano R, Naghavi M, Foreman K, et al. Global and regional mortality from 235 causes of death for 20 age groups in 1990 and 2010: a systematic analysis for the Global Burden of Disease Study 2010. Lancet. 2012;380(9859):2095-2128.

3. Zheng YM, Tuppin P, Hubert A, et al. Environmental and dietary risk factors for nasopharyngeal carcinoma: a case-control study in Zangwu County, Guangxi, China. Br J Cancer. 1994;69(3):508-514.

4. Chang ET, Adami HO. The enigmatic epidemiology of nasopharyngeal carcinoma. Cancer Epidemiol Biomarkers Prev. 2006;15(10): 1765-1777.

5. Lam KO, Lee AW, Choi CW, et al. Global pattern of nasopharyngeal cancer: correlation of outcome with access to radiation therapy. Int J Radiat Oncol Biol Phys. 2016;94(5):1106-1112.

6. Dou H, Hu D, Lam C, Liu Y, Wang X, Zhang W. Retrospective analysis of results of treatment for nasopharyngeal carcinoma in Macao. Chin J Cancer Res. 2014;26(2):148-158.

7. Ferlay J, Soerjomataram I, Dikshit R, et al. Cancer incidence and mortality worldwide: sources, methods and major patterns in GLOBOCAN 2012. Int J Cancer. 2015;136(5):E359-E386.
8. Haleshappa RA, Thanky AH, Kuntegowdanahalli L, Kanakasetty GB, Dasappa L, Jacob L. Epidemiology and outcomes of nasopharyngeal carcinoma: Experience from a regional cancer center in Southern India. South Asian J Cancer. 2017;6(3):122-124.

9. Chua MLK, Wee JTS, Hui EP, Chan ATC. Nasopharyngeal carcinoma. Lancet. 2016;387(10022):1012-1024.

10. Xu ZJ, Zheng RS, Zhang SW, Zou XN, Chen WQ. Nasopharyngeal carcinoma incidence and mortality in China in 2009. Chin J Cancer. 2013;32(8):453-458.

11. Shanmugaratnam K, Sobin LH. Histological Typing of Tumours of the Upper Respiratory Tract and Ear. 2nd ed. Berlin: Springer; 1991.

12. Prasanth R, Gopinath D. Effect of $\mathrm{ZnO}$ nanoparticles on nasopharyngeal cancer cells viability and respiration. Appl Phys Lett. 2013;102: 113702.

13. Luo H, Lu L, Yang F, et al. Nasopharyngeal cancer-specific therapy based on fusion peptide-functionalized lipid nanoparticles. ACS Nano. 2014;8(5):4334-4347.

14. Dreaden EC, Alkilany AM, Huang X, Murphy CJ, El-Sayed MA. The golden age: gold nanoparticles for biomedicine. Chem Soc Rev. 2015;41:2740-2779.

15. Ghosh G, Han G, De M, Kim KC, Rotello VM. Gold nanoparticles in delivery applications. Adv Drug Deliv Rev. 2008;60:1307-1315.

16. Turkevich J, Stevenson PC, Hillier J. A study of the nucleation and growth processes in the synthesis of colloidal gold. Discuss Faraday Soc. 1951;11:55-75.

17. Brust M, Walker M, Bethell D, Schriffin DJ, Whyman R. Synthesis of thiol-derivatised gold nanoparticles in a two-phase Liquid-Liquid system. J Chem Soc Chem Commun. 1994(7):801-802.

18. Mittal AK, Chisti Y, Banerjee UC. Synthesis of metallic nanoparticles using plant extracts. Biotechnol Adv. 2013;31(2):346-356.

19. Dubey SP, Lahtinen M, Sillanpää M. Tansy fruit mediated greener synthesis of silver and gold nanoparticles. Process Biochem. 2010; 45(7):1065-1071.

20. Zhan G, Huang J, du M, et al. Green synthesis of Au-Pd bimetallic nanoparticles: Single-step bioreduction method with plant extract. Mater Lett. 2011;65(19-20):2989-2991.

21. Roshy JC, Ilanchezhian R, Patgiri BJ. Therapeutic potentials of kantakari (Solanum xanthocarpum Schrad. and Wendl). Ayurpharm Int J Ayur Alli Sci. 2012;1:46-53.

22. Patel VB, Rathod IS, Patela JM, Brahmbhatta MR. Anti-urolithiatic and natriuretic activity of steroidal constituents of Solanum xanthocarpum. Der Pharma Chemica. 2010;2:173-176.

23. Singh OM, Singh TP. Phytochemistry of Solanum xanthocarpum: an amazing traditional healer. $J$ Sci Ind Res. 2010;69:732-740.

24. Kumar S, Pandey AK. Medicinal attributes of Solanum xanthocarpum fruit consumed by several tribal communities as food: an in vitro antioxidant, anticancer and anti HIV perspective. BMC Complement Altern Med. 2014;14(1):112.

25. Kumar S, Sharma UK, Sharma AK, Pandey AK. Protective efficacy of Solanum xanthocarpum root extracts against free radical damage: phytochemical analysis and antioxidant effect. Cell Mol Biol. 2012; 58(1):174-181.

26. Kuo KW, Hsu SH, Li YP, et al. Anticancer activity evaluation of the solanum glycoalkaloid solamargine. Triggering apoptosis in human hepatoma cells. Biochem Pharmacol. 2000;60(12):1865-1873.

27. Liu B, Ordonez-Ercan D, Fan Z, Edgerton SM, Yang X, Thor AD. Downregulation of erbB3 abrogates erbB2-mediated tamoxifen resistance in breast cancer cells. Int J Cancer. 2007;120(9):1874-1882.

28. Barahuie F, Saifullah B, Dorniani D, et al. Graphene oxide as a nanocarrier for controlled release and targeted delivery of an anticancer active agent, chlorogenic acid. Mater Sci Eng C Mater Biol Appl. 2017;74: 177-185.

29. Dorniani D, Saifullah B, Barahuie F, et al. Graphene oxide-gallic acid nanodelivery system for cancer therapy. Nanoscale Res Lett. 2016; 11(1):491. 
30. Huang X, El-Sayed MA. Gold nanoparticles: Optical properties and implementations in cancer diagnosis and photothermal therapy. $J A d v$ Res. 2010;1(1):13-28.

31. Thakor AS, Jokerst J, Zavaleta C, Massoud TF, Gambhir SS. Gold nanoparticles: a revival in precious metal administration to patients. Nano Lett. 2011;11(10):4029-4036.

32. Giljohann DA, Seferos DS, Daniel WL, Massich MD, Patel PC, Mirkin CA. Gold nanoparticles for biology and medicine. Angew Chem Int Ed Engl. 2010;49(19):3280-3294.

33. Mohseni N, Sarvestani FS, Ardestani MS, Kazemi-Lomedasht F, Ghorbani M. Inhibitory effect of gold nanoparticles conjugated with interferon gamma and methionine on breast cancer cell line. Asian Pac J Trop Biomed. 2016;6(2):173-178.

34. Rajeshkumar S. Anticancer activity of eco-friendly gold nanoparticles against lung and liver cancer cells. Journal of Genetic Engineering and Biotechnology. 2016;14(1):195-202.

35. Kumar D, Mutreja I, Chitcholtan K, Sykes P. Cytotoxicity and cellular uptake of different sized gold nanoparticles in ovarian cancer cells. Nanotechnology. 2017;28(47):475101.

36. Baharara J, Ramezani T, Divsalar A, Mousavi M, Seyedarabi A. Induction of apoptosis by green synthesized gold nanoparticles through activation of caspase- 3 and 9 in human cervical cancer cells. Avicenna J Med Biotechnol. 2016;8(2):75-83.

37. Selim ME, Hendi AA. Gold nanoparticles induce apoptosis in MCF-7 human breast cancer cells. Asian Pac J Cancer Prev. 2012;13(4): 1617-1620.
38. Liou GY, Storz P. Reactive oxygen species in cancer. Free Radic Res. 2010;44(5):479-496.

39. Yin J-J, Liu J, Ehrenshaft M, et al. Phototoxicity of nano titanium dioxides in HaCaT keratinocytes - Generation of reactive oxygen species and cell damage. Toxicol Appl Pharmacol. 2012;263(1):81-88.

40. Fu PP, Xia Q, Sun X, Yu H. Phototoxicity and environmental transformation of polycyclic aromatic hydrocarbons (PAHs)-light-induced reactive oxygen species, lipid peroxidation, and DNA damage. J Environ Sci Health C Environ Carcinog Ecotoxicol Rev. 2012;30(1): $1-41$.

41. Xia Q, Yin JJ, Fu PP, Boudreau MD. Photo-irradiation of Aloe vera by UVA - formation of free radicals, singlet oxygen, superoxide, and induction of lipid peroxidation. Toxicol Lett. 2007;168(2):Boudreau MD (2007):165-175.

42. Hoskins C, Cuschieri A, Wang L. The cytotoxicity of polycationic iron oxide nanoparticles: common endpoint assays and alternative approaches for improved understanding of cellular response mechanism. J Nanobiotechnology. 2012;10:15.

43. Tanida I, Ueno T, Kominami E. LC3 and Autophagy. Methods Mol Biol. 2008;445:77-88.

44. Li JJ, Hartono D, Ong CN, et al. Autophagy and oxidative stress associated with gold nanoparticles. Biomaterials. 2010;31(23): 5996-6003.
International Journal of Nanomedicine

\section{Publish your work in this journal}

The International Journal of Nanomedicine is an international, peerreviewed journal focusing on the application of nanotechnology in diagnostics, therapeutics, and drug delivery systems throughout the biomedical field. This journal is indexed on PubMed Central, MedLine, CAS, SciSearch $®$, Current Contents $\AA /$ Clinical Medicine,

\section{Dovepress}

Journal Citation Reports/Science Edition, EMBase, Scopus and the Elsevier Bibliographic databases. The manuscript management system is completely online and includes a very quick and fair peer-review system, which is all easy to use. Visit http://www.dovepress.com/ testimonials.php to read real quotes from published authors. 